\title{
Resistir la Covid-19. Intersecciones en la Educación de Ciudad Juárez, México
}

\author{
Resist the Covid-19. Intersections in Education in Ciudad \\ Juárez, Mexico
}

\author{
Evangelina Cervantes Holguín * \\ Pavel Roel Gutiérrez Sandoval \\ Universidad Autónoma de Ciudad Juárez, México
}

\begin{abstract}
En el 2020, México se enfrentó a la nueva enfermedad por coronavirus declarada como emergencia de salud pública de importancia internacional. En respuesta, durante el mes de marzo la Secretaría de Educación Pública y la Secretaría de Salud implementaron un conjunto de medidas para prevenir y contener la propagación del virus. Los objetivos son: identificar las acciones implementadas por el gobierno y analizar sus implicaciones pedagógicas, sociales y económicas. Se desarrolló un ejercicio cualitativo de tipo documental que permitió la localización, clasificación, selección, análisis y comparación de diversos documentos. Como resultado se identificaron tres acciones prioritarias y 20 medidas de atención primaria para su implementación en todo el territorio nacional. Se encontró que el cierre de las escuelas reveló un conjunto de desafíos para las autoridades educativas, el profesorado y las familias, en tanto la ejecución de estas medidas se configura en un entramado de circunstancias educativas, sociales y económicas que, en suma, profundizan la desigualdad educativa. Se concluye que escuelas y profesorado son agentes clave en la contención sanitaria, sin embargo, las condiciones de las escuelas y las características socioeconómicas de las comunidades definen la experiencia de prevención y confinamiento.
\end{abstract}

Descriptores: Educación a distancia; Educación sanitaria; Enseñanza pública; Política de la salud; Virus.

In 2020, Mexico faced the new coronavirus disease declared as a public health emergency of international importance. In response, during the month of March the Ministry of Public Education and the Ministry of Health implemented a set of measures to prevent and contain the spread of the virus. The objectives are: first, to identify the actions implemented by the Mexican government, and to analyze its pedagogical, social and economic implications. A qualitative documentary exercise was carried out, it allowed the location, classification, selection, analysis and comparison of various documents. As a result, three priority actions and 20 primary care measures were identified for their implementation throughout the national territory. It was found that the closure of the schools revealed a set of challenges for the educational authorities, teachers and families, while the execution of these measures is configured in a network of educational, social and economic circumstances that deep in educational inequality. It is concluded that schools and teachers are key agents in health containment, however, the conditions of the schools and the socioeconomic characteristics of the communities define the experience of prevention and confinement.

Keywords: Distance education; Health education; Public education; Health policy; Virus.

*Contacto: evangelina.cervantes@uacj.mx

ISSN: 2254-3139

www.rinace.net/riejs/

revistas.uam.es/riejs
Recibido: $\quad 2$ de abril 2020

$1^{\text {a }}$ Evaluación: 18 de abril 2020

$2^{\text {a }}$ Evaluación: 30 de abril 2020

Aceptado: $\quad 2$ de mayo 2020 


\section{Introducción}

El 2020 será recordado como el año del Coronavirus 2019 (Covid-19). Tan solo en sus primeras semanas, el mundo fue testigo de su surgimiento, "cuya letalidad estimada durante los primeros dos meses de su aparición, oscila[ba] entre $2-3 \%$, con un $10 \%$ de la población afectada presentando manifestaciones clínicas graves" (Rodríguez-Morales et al., 2020, p. 3). El virus, localizado el 12 de diciembre de 2019 en la ciudad de Wuhan, en la República Popular de China, llegó a Latinoamérica el 25 de febrero de 2020, cuando el gobierno de Brasil confirmó el primer caso en la región. El 28 de febrero de 2020, México acreditó el primer caso en el territorio nacional (Secretaría de Educación Pública (SEP), 2020a); mientras en el Estado de Chihuahua, el primer caso confirmado se presentó el 17 de marzo de 2020 en Ciudad Juárez (Gobierno del Estado de Chihuahua, 2020a).

El 30 de enero de 2020, la Organización Mundial de la Salud (OMS, 2020a) declaró el brote del nuevo coronavirus como una Emergencia de Salud Pública de Importancia Internacional (ESPII) y recomendó a los países "adoptar medidas de contención, como la vigilancia activa, la detección temprana, el aislamiento y el manejo de los casos, el seguimiento de contactos y la prevención de la propagación del 2019-nCoV” (párr. 35). Para el 11 de marzo de 2020, la OMS (2020b), considerando que el número de casos se había multiplicado y miles de personas luchaban por su vida, declaró a la Covid-19 como pandemia y reiteró la obligación de los países para diseñar una estrategia integral dirigida a prevenir las infecciones, reducir los efectos, detectar, proteger y tratar. Además, la invitación incluía hacer de la experiencia una oportunidad para innovar y aprender. Con todo, en el mismo comunicado se reconocía que algunos países carecían de capacidad, recursos y determinación para frenar el virus (OMS, 2020c).

En correspondencia, el 14 de marzo de 2020, la Secretaría de Educación Pública (SEP, 2020b) del Gobierno de México, informó a la comunidad en general las medidas de prevención para el sector educativo en toda la nación. En este escenario, el trabajo parte del supuesto de que el éxito de una política pública se determina, en gran medida, en la fase de implementación -posterior a la construcción de los problemas y al diseño de la política-, por lo que el ejercicio analítico se centra en las decisiones gubernamentales tomadas durante el mes de marzo. Así, el presente trabajo tiene como objetivos: primero, identificar las acciones implementadas en la educación básica por el gobierno mexicano ante la Covid-19; y, segundo, analizar sus implicaciones pedagógicas, sociales y económicas, tomando como referente la experiencia de Ciudad Juárez, Chihuahua ubicada en la frontera norte. En esta dirección el texto ofrece un acercamiento a los estudios iniciales sobre la Covid y sus implicaciones educativas en el contexto internacional que sirven de referente para el análisis de las acciones implementadas en el contex to mexicano. Para ello, se describen cronológicamente las medidas de prevención propuestas por la SEP y la Secretaría de Salud, acciones que posteriormente se contextualizan para valorar su pertinencia.

\section{Revisión de la literatura}

A la fecha, la Covid-19 se configura como objeto de estudio principalmente de la investigación en salud. En atención a los objetivos del presente trabajo se buscaron artículos de investigación acerca del tema que cumplieran cuatro condiciones: a) artículos científicos, resultado de una investigación; b) publicados en revistas arbitradas que dieran 
cuenta de su calidad académica; c) centrados en el análisis de la Covid; y d) con referencia el ámbito educativo. Como resultado se localizaron cinco artículos publicados durante el mes de marzo en diferentes bases de datos. En conjunto, estos artículos configuran un marco referencial en cierne sobre el coronavirus y la educación.

Brooks y otros (2020) y Wang y otros (2020) coinciden en su interés en los efectos en la infancia del cierre de escuelas como medida de emergencia sanitaria. En el primer caso, Brooks y otros (2020) realizaron un estudio con el objetivo de examinar la literatura existente sobre las actividades y los contactos de los niños realizados fuera del hogar durante el cierre de escuelas no planificadas; en el segundo, Wang y otros (2020) analizaron los efectos en la salud física y mental de los niños ante el cierre prolongado de las escuelas y el confinamiento. Según el estudio, el gobierno chino ordenó el cierre de las escuelas como medida de emergencia para evitar la propagación de la infección, situación que se atendió con éxito por parte del sistema administrativo y la colaboración de los maestros, quienes hacen esfuerzos en todos los niveles para crear cursos en línea, disponibles a través de transmisiones de televisión e internet en un tiempo récord. Este estudio y el realizado por Ornell y otros (2020) ponen énfasis en la salud mental. En el último se analizaron las implicaciones directas de la Covid-19 en la vida diaria y la salud mental de la población sobre la idea de que la información falsa o dudosa acerca de los factores relacionados con la transmisión del virus, el período de incubación, su alcance geográfico, el número de infectados y la tasa de mortalidad real ha provocado inseguridad y miedo en la población.

Por su parte, Gudi y Tiwari (2020) analizan los efectos de la Covid-19 en la vida cotidiana -seguridad universal, gobierno, cuidado de la salud, empleo, educación y alimentación-, así como las lecciones que pueden derivarse para hacer un mundo mejor. Al respecto, Rodríguez-Morales y otros (2020) señalan la necesidad de mayor trabajo multidisciplinar para la prevención de la Covid-19 en América Latina.

Dada la limitada producción científica sobre la temática y la ausencia de trabajos en la región, la búsqueda se amplió dando como resultado la inclusión de un ensayo y dos artículos periodísticos. Desde Argentina, Bazán y Porta (2020) reflexionan "en la inmediatez, lo urgente y necesario de este turbulento mundo" (p. 1), sobre los aprendizajes y enseñanzas vitales que deja la Covid-19. A través de tres preguntas llaman "a reconstituir pedagogías que apuesten por sentidos vitales... generadoras de otras posibles narrativas experienciales acerca de esos mundos, como formas de vivir y sentir en tiempos turbulentos, pero también de pensar y experimentar futuros posibles fuera del laberinto" (p. 5).

En México, Schmelkes (2020) señala que, con la suspensión de clases presenciales en todas las escuelas del país, la brecha digital se convertirá en una brecha de aprendizaje, en especial, entre los estudiantes de educación básica que carecen de las habilidades de autorregulación y autodisciplina, así como entre aquellos que carecen de conexión a internet y computadoras en sus casas y zonas de residencia, por lo que propone emplear la televisión y la radio. Sobre el tema, Jarquín (2020) considera que la lucha contra la Covid-19 significó para México enfrentarse a los efectos de una crisis económica histórica, caracterizada por la desigualdad educativa probada en la inequidad en la infraestructura escolar, la sobrepoblación en las aulas, la insuficiencia de los insumos de higiene y la falta de acceso a la tecnología. Con todo, la experiencia también ofrece dos oportunidades: por un lado, experimentar las bondades de la educación a distancia y las plataformas digitales 
de aprendizaje - de la mano de los gigantes de la edubusiness-; por otro, repensar la formación para la ciudadanía, discutir el financiamiento educativo y apoyar al profesorado.

\section{Método}

El estudio se desarrolló con un enfoque metodológico cualitativo dirigido a comprender la complejidad de los fenómenos sociales (Galeano, 2004). En atención a los objetivos del trabajo, se empleó la investigación documental como modalidad, entendida como una "forma de investigar en la que se consolida de manera estructurada una opción epistemológica, un propósito, una ruta metodológica y un arsenal instrumental” (p. 55). En el proceso se siguió la propuesta de Sandoval (1996) consistente en cinco etapas: 1. Rastrear los documentos disponibles: en esta etapa se realizó una búsqueda en dos sentidos: el primero, implicó la localización de los documentos publicados por las secretarías de Educación y de Salud en el portal de la Presidencia de la República respecto a la Covid-19; el segundo, refirió a la identificación de investigaciones y documentos sobre el tema que permitieran contextualizar las acciones implementadas por el gobierno mexicano y contrastar su pertinencia; 2. Clasificar los documentos: con la intención de organizar los documentos se elaboró una matriz de resumen informativo que permitió recuperar el contenido general de cada escrito; 3. Seleccionar la información: una vez realizada la revisión panorámica de la información, esta se organizó considerando tres criterios: fecha, agentes educativos involucrados y ámbito de implementación; 4. Analizar el contenido: se realizó una lectura exhaustiva del material seleccionado y se separaron los extractos de mayor trascendencia, y; 5. Comparar la información: se confrontaron los elementos de los documentos consultados para identificar similitudes y contradicciones.

\section{Resultados}

Para atender las recomendaciones de la OMS frente a la Covid-19, la SEP y la Secretaría de Salud presentaron 20 medidas de atención prioritaria con la intención de "contribuir a preservar la salud de niñas, niños, adolescentes y jóvenes, así como del resto de la comunidad en todos los planteles educativos del país" (SEP, 2020b, párr. 1). Estas medidas se presentan en orden cronológico:

14 de marzo de 2020

- El receso escolar, inicialmente programado en el calendario oficial del 06 al 17 de abril (SEP, 2019a), comprenderá del lunes 23 marzo al viernes 17 de abril, que en términos prácticos refiere a un periodo de 30 días, del 20 de marzo al 20 de abril.

- Durante este período se realizará limpieza profunda de las escuelas.

- Las labores escolares se reanudarán el lunes 20 de abril, siempre y cuando, se cuente con las condiciones determinadas por la autoridad sanitaria federal en cada plantel.

- Los contenidos se recuperarán para cumplir con los planes y programas establecidos en los días de receso.

- La SEP establecerá un sistema de Educación a Distancia electrónica y digital para la recuperación de contenidos de aprendizaje. 
- En los Consejos de Participación Escolar se instalará una comisión de salud que tendrá las siguientes tareas: a. Apoyar al Filtro Escolar; b. Coadyuvar en la higiene escolar; c. Comunicar permanentemente a la comunidad escolar las medidas sanitarias que correspondan, y; d. Relacionarse con el Comité Estatal para la Seguridad en Salud para informar y coordinar acciones.

- La instalación del Filtro corresponsable Escuela-madres y padres de familia para un oportuno reconocimiento de los protocolos señalados por la Secretaría de Salud. Este filtro requiere solicitar a los padres de familia que acrediten diariamente a la entrada de la escuela haber seguido las recomendaciones de higiene y de detección de síntomas de enfermedad, mediante un recado firmado donde señalen que: a) Lavaron las manos de sus hijos antes de ir a la escuela, y; b) No presenta fiebre, tos seca, dolor de cabeza y cuerpo cortado.

- Al interior de la escuela habrá un segundo filtro para que los padres de familia y tutores informen a las autoridades de los planteles escolares las incidencias en la salud del alumnado; en el salón de clases, los maestros deberán cerciorarse de que ningún alumno presente síntomas y proporcionarán gel antibacterial o, en su caso, agua y jabón.

- Los Gobiernos de cada estado dotarán de los materiales necesarios para este fin (Filtro Escolar).

- Se suspenden todas las actividades no-esenciales y los eventos escolares en el patio para honores cívicos, festivales, actividades deportivas, comunitarias, entre otras.

- Generar un acuerdo secretarial para modificar el calendario escolar en virtud de las medidas señaladas.

- Se recomienda el aislamiento preventivo (para el estudiantado).

- Las autoridades educativas locales deberán mantener estrecha comunicación con la autoridad sanitaria y proveer a sus escuelas de materiales de limpieza e higiene.

- Para toda información adicional respecto a la Covid-19 se creó el micro-sitio de la Secretaría de Salud en www.gob.mx/coronavirus

Las medidas anteriores, según la Subsecretaría de Prevención y Promoción de la Salud, corresponden a la fase de mitigación o contención comunitaria del coronavirus que se aplica, sin atender a una emergencia sanitaria.

16 de marzo de 2020

- En acuerdo con el Sindicato Nacional de los Trabajadores de la Educación, se estableció el periodo de aislamiento voluntario preventivo para docentes y personal administrativo de todos los niveles de enseñanza, del 24 marzo al 17 abril, salvo para las tareas esenciales como pago de nómina y limpieza.

- A las medidas señaladas se suman: Evitar reuniones en los hogares para tener el menor contacto social posible. Propiciar el cuidado de las personas de la tercera edad en las familias, magisterio y personal administrativo. Coadyuvar al aprendizaje en casa ya que se realizarán actividades académicas a distancia (SEP, 2020d). 
20 de marzo de 2020

- Como una opción de aprendizaje, la SEP en coordinación con el Sistema Público de Radiodifusión del Estado Mexicano (SPR), la Dirección General de Televisión Educativa (DGTVE) y Canal Once Niñas y Niños 11.2 dispuso el programa Aprende en Casa por TV y en Línea que estará disponible del lunes 23 de marzo al viernes 17 de abril (SEP, 2020e).

23 de marzo de 2020

- Ante las condiciones diferenciadas de la sociedad mexicana, la SEP convocó al personal docente y directivo a emplear la herramienta teams de Microsoft para acceder a sesiones de trabajo y capacitación a distancia desde su propio aislamiento preventivo. En tanto, las personas que tengan dificultad para acceder a internet contarán con la programación de Teleprimaria, Telesecundaria y Telebachillerato, así como diversas plataformas para fortalecer las tareas escolares en casa y cubrir los contenidos de planes y programas de estudio (SEP, 2020f).

28 de marzo de 2020

- A partir del lunes 30 de marzo inició el programa de actualización y capacitación en línea como estrategia para la formación y capacitación del magisterio mexicano en el uso de las Tecnologías de la Información, Comunicación, Conocimiento y Aprendizaje Digitales (TICCAD) (SEP, 2020g).

31 de marzo de 2020

- El Consejo de Salubridad General (CSG) declara emergencia sanitaria nacional por epidemia de enfermedad generada por el virus SARS-CoV-2 (Covid-19), que implica la suspensión inmediata, del 30 de marzo al 30 de abril de 2020, de actividades no esenciales en los sectores público, privado y social, con la finalidad de mitigar la dispersión y transmisión del virus, disminuir la carga de enfermedad, sus complicaciones y muerte en la población (Secretaría de Salud, 2020).

En Chihuahua, las medidas anteriores se replicaron con apoyo de las secretarías locales de educación y salud, la Subdirección de epidemiología y la Dirección de prevención y control de enfermedades (Gobierno del Estado de Chihuahua, 2020a). En respuesta, la Subsecretaría de Educación Zona Norte -ubicada en Ciudad Juárez- verificó el seguimiento de las acciones de los gobiernos federal y estatal para la prevención del coronavirus en las escuelas de educación básica (Gobierno del Estado de Chihuahua, 2020b). La siguiente parte del trabajo se centra en abordar cada una de las acciones descritas a fin de analizar sus implicaciones pedagógicas, sociales y económicas.

\section{Discusión}

Desde la posición de Navarro (2008) el proceso de construcción de políticas públicas implica cuatro etapas: 1. Identificación de problemas públicos y su incorporación a la agenda de gobierno; 2. Formulación de alternativas y de decisión; 3. Implementación; y, 4. Evaluación de políticas públicas. En razón a los propósitos del trabajo, el análisis se centra en la fase de implementación que, alude a la tarea de conocer la trayectoria de una decisión, un conjunto de decisiones o de un sector de la actividad pública para identificar 
las circunstancias que contribuyen a su éxito o fracaso a fin de detectar fallos y realizar ajustes.

A partir del análisis, se considera que las medidas de prevención generadas por el gobierno mexicano se concentran en tres acciones prioritarias: 1 . El establecimiento de un periodo de aislamiento voluntario preventivo que implicó la reprogramación del periodo vacacional y ajuste al calendario de educación básica correspondiente al ciclo escolar 20192020; 2. El diseño de una estrategia nacional para la recuperación de los contenidos a efecto de cumplir con los planes y programas de educación básica, y; 3. La declaración de emergencia sanitaria nacional.

Con la intención de contextualizar las medidas y valorar su pertinencia, a continuación, se analizan según su ámbito de implementación.

\subsection{En la escuela}

En la línea temporal, estas medidas se aplicaron a partir del lunes 16 de marzo que la SEP emitió el Acuerdo 02/03/20 por el que se suspendieron las clases hasta el 23 de marzo, como acción preventiva para disminuir el impacto de propagación de la Covid-19 (SEP, 2020f), en tanto se consideró que en el entorno escolar las niñas, niños y adolescentes (NAA) son transmisores o contenedores de virus (SEP, 2020a).

\subsubsection{Suspender todas las actividades escolares no-esenciales}

De la experiencia internacional, una de las principales recomendaciones consistió en evitar permanecer en lugares públicos con altas concentraciones de personas, como transporte público masivo, teatros, cines, centros comerciales, oficinas, establecimientos educativos y restaurantes (Rodríguez-Morales et al., 2020). Sobre esta idea, la SEP ordenó suspender todas las actividades físicas, cívicas y masivas que se hubieran programado en la escuela. A nivel local, las autoridades refrendaron la suspensión de actividades no esenciales y eventos masivos (Gobierno del Estado de Chihuahua, 2020a).

\subsubsection{Establecer un plan de prevención, mitigación y contención de la Covid-19}

Este plan implicó atender seis medidas: 1. Instalar un Consejo de Participación Escolar; 2. Realizar limpieza profunda de las escuelas para reforzar las medidas de higiene; 3. Instalar el filtro corresponsable Escuela-madres y padres de familia; 4. Instalar un filtro básico; 5. Proveer a las escuelas de materiales de limpieza e higiene, y; 6. Dotar a las escuelas de los materiales necesarios para el filtro escolar.

La instalación de un Consejo de Participación Escolar se propuso como una medida para transformar las escuelas, con ayuda de la comunidad, en espacios saludables y seguros mediante la constitución del filtro escolar, la limpieza de las instalaciones y materiales didácticos, el desarrollo de hábitos de higiene personal y de las competencias para el autocuidado (SEP, 2020a). Según el Instituto Nacional para la Evaluación de la Educación (INEE) (2016) en las escuelas de educación primaria existen carencias importantes en la prevención y atención de contingencias. Sobre el punto, solo el 54,8\% contaba con un comité de seguridad y emergencia escolar.

Por otra parte, en el plan debía considerarse una jornada de limpieza en la escuela a cargo del director escolar. Si bien, primero se señaló que se proveerían los materiales de limpieza necesarios, en la sesión extraordinaria del Consejo Técnico Escolar, la SEP (2020h) delegaba la responsabilidad a la comunidad escolar para apoyar con dichos insumos. Lavar con agua, jabón y cloro se presentaba como la estrategia principal, sin embargo, a nivel 
nacional solo el $52,1 \%$ de las escuelas primarias tiene suficiente agua, el $41 \%$ tiene insuficiente y el 6,7\% no tiene (INEE, 2019a). A nivel nacional, la disponibilidad de agua para lavarse las manos es diferenciada: mientras que el 68,8\% de las escuelas cuentan con agua de la llave para lavarse las manos, el $26 \%$ dispone de agua en tambos u otros contenedores para lavarse las manos y el 5,1\% carecen de agua para tal fin (INEE, 2016). Al respecto, las comunidades de la periferia en Ciudad Juárez enfrentan la falta de agua potable y saneamiento, situación que limita su acceso a cierto nivel de bienestar (Córdova, 2018).

Entre los elementos del plan se distingue la incorporación de tres filtros (SEP, 2020a): a) Filtro Familiar, los responsables de familia identificarán en el hogar si sus hijos presentan síntomas de enfermedades respiratorias, desarrollarán los cuidados preventivos y prepararán las condiciones necesarias para el resguardo en casa. Además, las familias deberán promover hábitos de higiene y prevención como "lavarse las manos con frecuencia y correctamente, al menos durante 20 segundos con agua y jabón” (p. 15). Si bien, lavarse las manos es la primera línea de defensa contra la Covid-19 en tanto esta práctica podría reducir drásticamente la propagación y la eliminación de nuevos casos (Gudi y Tiwari, 2020), en Ciudad Juárez, al menos, 7.000 habitantes de la periferia carecen de agua potable (Córdova, 2018); b) Filtro escolar, se conformará con la participación de las familias y del personal directivo, docente, de apoyo y asistencia quienes tendrán las tareas de recibir la Carta de compromiso de corresponsabilidad firmada por los responsables de familia, pedir al alumnado lavarse las manos o aplicar gel antibacterial e informar a las autoridades de los casos identificados; y c) Filtro en el salón, el profesorado deberá identificar la presencia de síntomas entre el estudiantado e informar a la dirección escolar para que localice a su familia. Además, en apego a las recomendaciones sanitarias de la OMS (2020b), en el contexto escolar se debe impulsar la distancia social, a más de un metro de distancia, para evitar el contagio del virus por contacto físico. La medida se torna obsoleta en condiciones de hacinamiento, común en algunas escuelas del país en donde el $31 \%$ del profesorado a cargo de los tres grados superiores de educación primaria “perciben que su salón de clases es pequeño considerando el número de estudiantes que atiende” (INEE, 2016, p. 17); situación habitual en Ciudad Juárez donde cada docente "cuenta con 51\% más alumnos... que el resto del estado” (Instituto Municipal de Investigación y Planeación (IMIP, 2019, p. 113).

La participación de las familias representa un componente clave en el éxito del Plan de Prevención, sin embargo, en el país "se han identificado tensiones entre las expectativas de los padres de familia y las de los docentes. Los maestros se enfrentan a una participación limitada de las familias, quienes además la perciben como impuesta” (INEE, 2019b, p. 73), probablemente porque su colaboración se ha restringido a asuntos relacionados con sus aportaciones económicas para el mantenimiento y la operación de la escuela. Además, una proporción importante del alumnado en Ciudad Juárez son parte de la generación de la maquila, término empleado por Gutiérrez (1999) para aludir a los hijos de empleados madre y padre- en la industria maquiladora que quedan al cuidado de abuelas, tías, vecinas o, con frecuencia, solos; por lo que la participación de sus padres en la escuela se relega frente a las obligaciones laborales.

\subsubsection{Desarrollar un plan de aprendizaje en casa}

Esta medida se planteó con la intención de promover el aprendizaje en casa a través del desarrollo de actividades de manera remota y el acompañamiento de las familias, 
empleando los recursos educativos digitales para los distintos grupos disponibles en la red. En educación básica, en algunos casos el plan se convirtió en un cuadernillo de actividades con referencia a los libros de texto y diversos apoyos multimedia disponibles en internet; en la educación media, las tareas extraescolares habituales se extendieron y en la educación superior, las instituciones ampliaron sus herramientas para el trabajo académico en línea. Al respecto conviene considerar que, a nivel nacional, el $66 \%$ de las escuelas tiene suficiente luz, el $27,8 \%$ tiene insuficiente y el $6,0 \%$ no tiene; mientras, en el estado de Chihuahua, el 4,9\% de las escuelas carecen de luz y el 43,9 de conexión de internet (INEE, 2019a). En Ciudad Juárez solo el 73\% de las escuelas primarias cuenta con equipo de cómputo y de éstas únicamente el 41\% tiene acceso a internet (IMIP, 2019); además, solo el $35 \%$ de las personas dispone de computadora en casa y el $42,2 \%$ afirma "tener acceso a internet en su casa, mientras que solo el 7,8\% tiene acceso en su escuela, $21 \%$ en su trabajo y 26,1\% tiene acceso desde su celular" (Donjuan y Cruz, 2019, p. 3).

\subsection{En casa}

Estas medidas se aplicaron a partir del 23 de marzo de 2020, una vez establecido el aislamiento preventivo.

\subsubsection{Implementar el aislamiento preventivo del estudiantado}

Según Brooks y otros (2020), los cierres de emergencia en las escuelas frecuentemente se utilizan como intervenciones de salud pública durante brotes de enfermedades infecciosas en un intento por minimizar la propagación de la infección. En México esta medida trastocó la vida de más de 25 millones de estudiantes de educación básica (SEP, 2019b), 734.845 en el estado de Chihuahua y 289.777 en Ciudad Juárez (Gobierno del Estado de Chihuahua, 2020c).

La medida de aislamiento, que se viralizó con la frase \#quedateencasa, presentó una serie de desafíos. En el ámbito social - tal como lo concluyeron Brooks y otros (2020)-, los niños y sus familias continúan mezclándose con otras personas fuera del hogar, ya sea porque salían de casa o eran atendidos por personas externas, por lo que la efectividad del cierre resulta ambigua ante los problemas prácticos relacionados con el cuidado infantil y el impacto financiero; en el ámbito de la salud, Wang y otros (2020) concluyeron que, cuando los niños se ausentan de la escuela durante los periodos planificados -fines de semana y vacaciones-, son físicamente menos activos, pasan más tiempo frente a la pantalla, tienen patrones de sueño irregulares y dietas menos favorables, lo que resulta en un aumento de peso y una pérdida de la aptitud cardiorrespiratoria. Según la evidencia, es probable que estos efectos negativos en la salud se agraven cuando los niños están confinados en sus hogares sin actividades al aire libre e interacción con amigos de la misma edad. Además, dado que en la región un número importante de escuelas, con ayuda del gobierno, de particulares o de la propia comunidad, ofrecen desayunos escolares, el cierre de escuelas anula para el alumnado de bajos recursos la posibilidad de adquirir la única comida del día (Guerra, 2020); en el ámbito de la seguridad, Ornell y otros (2020) advierten que, en circunstancias de aislamiento, la inseguridad suele aumentar debido a las repercusiones económicas y sociales de la pandemia. En este aspecto, la propuesta gubernamental señalaba que el plan de aprendizaje en casa se diseñaría para que el alumnado continuara su proceso educativo desde el hogar, en un ambiente seguro, no obstante, la contingencia sanitaria en Ciudad Juárez ha provocado un aumento en la violencia doméstica que coloca a las mujeres e infantes en estado de vulnerabilidad (Barrera, 2020), situación preocupante en tanto que la ciudad encabeza los índices de violencia sexual infantil en el país. Los 
responsables son familiares -tío, abuelo o persona cercana al menor- que, en la dinámica del juego, cariño y atención encubren la violencia y obstaculizan la búsqueda de justicia (Martínez, 2019).

El ámbito económico constituye el desafío de mayor complejidad. En Ciudad Juárez existen 300.444 trabajadores del sector manufacturero y más de 28.000 personas que laboran en la informalidad y sin prestaciones -empleadas domésticas, vendedores de comida rápida, meseros y mecánicos-, que enfrentan dificultades para sobrevivir durante la contingencia (González, 2020; Lara, 2020). Al respecto, la Organización Internacional del Trabajo (OIT) urgió a las autoridades mexicanas a "prestar apoyo inmediato a los sectores y grupos de población más afectados, en particular a las empresas y los trabajadores de la economía informal” (párr. 2). Ante el dilema de morir por la Covid-19 o morir de hambre se señaló la necesidad de apoyar el empleo y generar acciones complementarias que garanticen el suministro suficiente de alimentos y demás productos de primera necesidad, considerando que las medidas de encierro parcial o confinamiento solo serán efectivas con apoyo directo a trabajadores, en especial a las mujeres. En este escenario se redimensionan los conceptos de necropolítica de Mbembe (2011) y de biopolítica de Foucault (2012), en tanto que los gobiernos de hoy se enfrentan al reto de asegurar el acceso igualitario a la salud y a la educación; quedando en manos de la política asegurar la existencia de las personas o promover la idea del carácter desechable de la vida humana (Bazán y Porta, 2020).

\subsubsection{Implementar un plan de aprendizaje en casa}

De forma complementaria se implementó el proyecto Aprende en Casa por TV y en Línea que permitió que los contenidos de los planes de estudio vigentes se desarrollaran en programas de televisión con el fin de compensar la ausencia del alumnado durante el periodo de contingencia (SEP, 2020e). Esta estrategia se basó en dos supuestos: primero, la capacidad de los responsables de familia para acompañar el proceso educativo en casa y, segundo, la disponibilidad de tiempo de los alumnos para el trabajo escolar. Según el INEE (2019a) únicamente el 55,1\% de los alumnos de sexto de primaria afirmó que su madre contaba con estudios de secundaria completa o más. En el municipio de Juárez, según datos del 2015, el grado promedio de escolaridad es de 9.65 años y un 7,7\% de la población entre 6 a 14 no sabe leer y escribir, dato relevante en tanto en la ciudad el cuidado infantil se desarrolla por los hermanos mayores (IMIP, 2019). Respecto a la disponibilidad de tiempo para el trabajo escolar, una parte de los alumnos se dedica a diversas actividades no-escolares, por ejemplo: el 13\% dedica más de tres horas al día a quehaceres del hogar, el $13 \%$ participa en el trabajo o negocio familiar y el 9,5\% trabaja por cuenta propia o como empleado (INEE, 2019a) lo que limita la posibilidad de cumplir con las tareas escolares.

En esta línea, se consideró generar una estrategia de Educación a Distancia para la recuperación de contenidos de aprendizaje. La medida fue implementada con rapidez por las instituciones de educación superior que ya contaban con herramientas de educación virtual, por ejemplo, a solo unos días la universidad de la ciudad implementó el Programa de Continuidad Académica Virtual (UACJ, 2020), sumándose a las escuelas y universidades de todo el mundo que han cambiado sus clases presenciales a cursos en línea (Gudi y Tiwari, 2020). La experiencia fue menos contundente en la educación media y básica donde los acercamientos a los entornos virtuales han sido limitados, probablemente porque las líneas de acción del gobierno mexicano para el acceso y uso de las Tecnologías de la Información y la Comunicación se han centrado en la dotación de recursos dejando 
al margen la capacitación de los docentes (INEE, 2019a), por lo que a pesar de los esfuerzos de algunos profesores por ofrecer una docencia digital que, requiere de habilidades específicas distintas a las acuñadas en la presencialidad (Ruiz y Aguirre, 2015), esta consistió en la digitalización de los materiales y el uso improvisado de diversas herramientas en línea, develando una experiencia virtual desorganizada.

Para atender la falta de capacitación simultáneamente se animó al profesorado a participar en los programas de actualización y capacitación -en forma de diplomados, cursos, nanocursos y conferencias- para el uso de las TICCAD ofertados por la SEP, la Fundación Carlos Slim y la Fundación Telefónica referentes a la mediación tecnológica, la gestión de ambientes virtuales, tecnologías para el aprendizaje, innovación educativa, ofimática, Microsoft teams, búsqueda en internet, saberes digitales docentes, entre otros (SEP, 2020c). Si bien, la propuesta formativa se centra en la capacitación técnica para la docencia en entornos virtuales, la emergencia sanitaria invita a reflexionar sobre la fragilidad de la escolarización de los procesos de aprendizaje. Para Bazán y Porta (2020) se requiere de un ejercicio reflexivo acerca de la pedagogía en términos vitales:

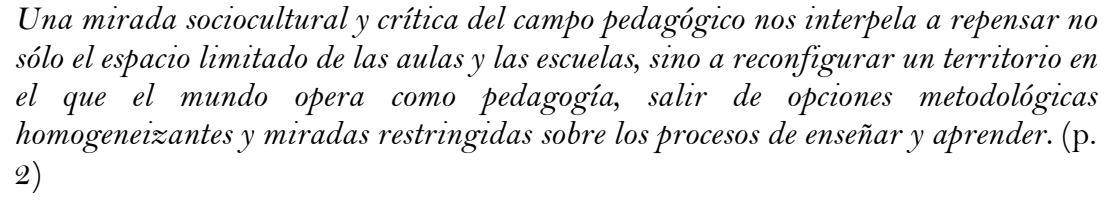

\subsubsection{Aislamiento voluntario preventivo para docentes y personal administrativo}

A partir del 24 de marzo, la SEP autorizó el aislamiento voluntario preventivo para el personal docente y administrativo en todos los niveles de enseñanza pública. La medida concernió a más de dos millones de docentes de educación básica a nivel nacional y a 32,988 a nivel estatal (SEP, 2019b). El confinamiento refiere a una experiencia diferenciada según los índices de pobreza en que vive una parte del magisterio mexicano. Para el INEE (2015) los docentes "ubicados en contextos de alta vulnerabilidad social enfrentan mayores retos que sus pares que laboran en ambientes de menor marginación y pobreza" (p. 29). En Ciudad Juárez, desde la última década los esfuerzos gubernamentales y de la sociedad civil se han dirigido al combate de la pobreza donde un $26 \%$ de las personas se encuentran en esta situación, sobre todo, en las colonias que rodean al centro histórico, el norponiente y el surponiente de la ciudad (Medina, Bass y Fuentes, 2019; Plan Estratégico de Juárez, 2020).

Los docentes, al igual que la población en general, se enfrentan a los efectos de la Covid19 en la vida cotidiana, como el cierre de escuelas, empresas y lugares públicos, cambios en las rutinas de trabajo y la organización familiar. Para Ornell y otros (2020), además de enfrentarse al miedo a la muerte, el aislamiento conlleva sentimientos de impotencia y abandono, que se suman a las manifestaciones del burnout -fatiga física y mental, dolores de cabeza, insomnio, irritabilidad, frustración, problemas gastrointestinales y cardiacospresentes en la vida del profesorado en Chihuahua (Rodríguez, Guevara y Viramontes, 2017).

La cuarentena mundial sugiere que, para salvarnos, "debemos permanecer alejados de nuestros semejantes” (Bazán y Porta, 2020, p. 2), por lo que es necesario diseñar políticas públicas "con rostro humano... en aquellas funciones básicas que permiten un mejor vivir, más igualitario, acompañándonos y no a nuestras espaldas, para escuchar y no para hacer oídos sordos, desarrollar la empatía y la antipatía, ampliar derechos y no limitarlos” (p. 2). 


\section{Conclusiones}

El presente trabajo permitió identificar las acciones implementadas por el gobierno federal y respaldadas por los gobiernos estatal y municipal ante la Covid-19. Las 20 medidas de prevención se identificaron como estrategias de salud pública y educación sanitaria en correspondencia a las orientaciones estratégicas propuestas por la OMS (2020a) para contener la propagación del virus. Según Bazán y Porta (2020), la (in)capacidad de los gobiernos para enfrentar a la Covid-19 demuestra que el acceso a la salud y a la educación depende de la lógica del mercado.

En atención a los propósitos del trabajo, cada medida fue analizada en lo particular para situarla en su contexto y conocer los problemas en su ejecución a fin de analizar sus implicaciones pedagógicas, sociales y económicas. En general, las medidas colocan a las escuelas y al profesorado como agentes clave en la prevención del contagio y la contención sanitaria, sin embargo, el cierre de las escuelas reveló no sólo la interrupción del aprendizaje, sino un conjunto de desafíos para las autoridades educativas, el profesorado y las familias en torno a la capacidad de los padres para acompañar la educación en casa, el acceso a las plataformas digitales, la formación docente en el uso de las tecnologías y el cuidado infantil, entre otros.

A pesar de los esfuerzos de los distintos niveles del gobierno y de las propias comunidades escolares, la valoración sobre la pertinencia de las medidas de prevención constituye una tarea pendiente, debido a dos elementos: a) La complejidad del hecho: Para RodríguezMorales y otros (2020) la propagación del virus se determina por diversos factores como los niveles de urbanización, número de viajes aéreos y condiciones socioeconómicas de cada población que rebasan las posibilidades de influencia escolar, y; b) La ausencia de mecanismos para la evaluación: Desde la perspectiva de Ornell y otros (2020), en países en desarrollo -entre ellos México-, con marcada disparidad social, bajos niveles de educación y cultura humanitaria cooperativa, se carece de parámetros para estimar el impacto de este fenómeno en la salud o el comportamiento mental de la población. Para Bazán y Porta (2020), la experiencia puede interpretarse como "el desenlace de la narrativa moderna sobre el progreso indefinido y a la vez la contracara asociada a la desigualdad, la pobreza y la necropolítica” (p. 1).

Con todo, se concluye que las condiciones de las escuelas y las características socioeconómicas de las comunidades determinan la experiencia de prevención y confinamiento. Según la información oficial, en las escuelas existen brechas que definen la forma en que estudiantes, docentes y familias viven la Covid-19. A nivel nacional, las comunidades con mayor necesidad tienen mayores dificultades para afrontar la contingencia y resistir el confinamiento, lo que se traduce en desigualdades para el acceso a la educación y la salud. En Ciudad Juárez, se infiere que la población escolar de las colonias de la periferia o de zonas con alta vulnerabilidad social -donde se concentra el $40 \%$ de la población-, afrontarán un escenario de mayor adversidad dadas las condiciones de pobreza y rezago en que viven (Medina et al., 2019). En estos espacios, la población infantil entre 5 y 12 años se enfrenta, al menos, a 135 factores que los ponen en riesgo, entre los que se encuentra la falta de acceso a la educación, a la alimentación, al servicio médico, a un espacio de cuidado digno, a espacios seguros, entre otros (López, 2019).

Entre las acciones, sobresalen las dirigidas a la formación docente: por un lado, se ofertó una serie de estrategias de formación para el profesorado en el uso de las tecnologíasf; por 
otro, la política de formación ignoró la necesidad de atender la salud física y mental de los docentes, en especial, porque las medidas reiteran la idea del autocuidado. Desde la posición de Bazán y Porta (2020) promover el autocuidado docente es una forma de humanización de la vida en la que "cuidarse para cuidar nos llama a convertirnos en sujetos, a apostar por la vida en contexto de socialidad" (p. 2).

Siguiendo la recomendación de la OMS (2020b), los documentos considerados en el trabajo coinciden en convertir la experiencia frente a la Covid-19 en una oportunidad de aprendizaje. En la historia reciente, México se ha enfrentado a la aparición del Síndrome Respiratorio Agudo Grave (SRAS), a la influenza aviar H5N 1 y a la influenza A, subtipo H1N1 que ameritó en abril del 2009 el "cierre de escuelas y colegios, así como la implementación masiva de medidas de precaución y manejo de la epidemia” (Cortés, 2009, p. 85). La información y el conocimiento acumulado frente a estas enfermedades representa un insumo importante para enfrentar tanto a la Covid-19 como a las contingencias futuras. El peligro radica en empezar de nuevo ante cada emergencia desechando los errores y aciertos de lo realizado en el pasado.

En un marco de equidad, esta información podría servir como referente para diseñar políticas y protocolos de actuación que permitan enfrentar las emergencias sanitarias con eficacia y determinar los recursos y estrategias necesarias para compensar las desigualdades. De acuerdo con la propuesta de Navarro (2008), en el proceso de las políticas públicas, frente a la fase de implementación surge la etapa de evaluación para estimar "la utilidad de los programas de intervención con el fin de producir evidencia empírica... que permita valorar y perfeccionar los programas públicos" (p. 247). Dado que el presente trabajo se centra en la fase inicial de implementación, ofrece la posibilidad de reflexionar acerca de la pertinencia de las medidas implementadas con el propósito de generar conocimiento que oriente el diseño de acciones correctivas, ajustes y estrategias de seguimiento para enfrentar con mayores elementos la contingencia sanitaria.

Entre las limitaciones puede señalarse la producción simultánea de estudios sobre la Covid-19 y sus consecuencias en la educación y la vida escolar. Las investigaciones sobre el tema están en curso y, hasta ahora, se centran en los efectos que el virus ha dejado en la vida cotidiana. Una de las limitantes refiere a la ausencia de información oficial y estudios sobre las condiciones de trabajo docente, la infraestructura escolar, la experiencia en entornos virtuales de aprendizaje, la vida cotidiana del estudiantado, entre otras que permitan comprender la dinámica educativa de Ciudad Juárez. Frente a la Covid-19, se sugiere la realización de nuevos estudios que: profundicen en las estrategias desarrolladas por los colectivos docentes, las direcciones escolares y las familias para sobrevivir el aislamiento, promover el aprendizaje y atender la educación socioemocional; evalúen las acciones implementadas, sobre todo, aquellas dirigidas a las poblaciones vulnerables que requieren de ajustes razonables; recuperen la experiencia en términos de aprendizaje colectivo e individual, entre otros.

Finalmente, nos sumamos al anhelo de Bazán y Porta (2020):

La pandemia que intentamos sobrellevar nos llama a la introspección, la aceptación del fin de las promesas de la modernidad, pero también nos interpela en nuestro lugar de humanidad y en el compromiso a tomar para pensar futuros posibles. Son tiempos urgentes, pero óptimos para generar nuevas condiciones que nos permitan potenciar otras narrativas acerca del mundo... Los signos de los tiempos presentes abren lugar al pánico y desensibilización, pero son ante todo un desafío para quienes desde la enseñanza militamos por restituir aquello que nos hace humanos. (p. 4) 


\section{Referencias}

Barrera, F. (6 de abril de 2020). Aumenta violencia doméstica durante contingencia. Netnoticias. https://netnoticias.mx/de-interes/aumenta-violencia-domestica-durante-contingencia/.

Bazán, S. y Porta, L. (2020). El mundo como pedagogía. Gestos vitales en tiempos de Covid-19. CIMED.

Brooks, S. K., Smith, L. E., Webster, R. K., Weston, D., Woodland, L., Hall, I. y Rubin, G. J. (2020). The impact of unplanned school closure on children's social contact: Rapid evidence review. Eurosurveillance, 25(13), 21-30.https://doi.org/10.2807/1560-7917.ES.2020.25.13.2000188

Córdova, G. (2018). Acción pública local: Una alternativa para dotar de agua potable a las colonias de la periferia de Ciudad Juárez, Chihuahua. Estudios Demográficos y Urbanos, 33(2), 505-534. https://doi.org/10.24201/edu.v33i2.1730

Cortés, J. A. (2009). Pandemia de influenza A por nuevo virus H1N1. Revista de la Facultad de Medicina, 57(2), 85-88.

Donjuan, E. y Cruz, J. E. (2019). Así estamos Juárez en internet y redes sociales. http://planjuarez.org/wp-content/uploads/2018/12/aejinternet.pdf.

Foucault, M. (2012). Nacimiento de la biopolítica: Curso del collège de France (1978-1979). Ediciones Akal.

Galeano, M. E. (2004). Diseño de proyectos en la investigación cualitativa. Fondo Editorial Universidad EAFIT.

Gobierno del Estado de Chihuahua. (2020a). Está en Juárez el primer caso de Covid-19 confirmado en Chihuahua. http://www.chihuahua.gob.mx/contenidos/esta-en-juarez-primer-caso-deCovid-19-confirmado-en-chihuahua

Gobierno del Estado de Chihuahua. (2020b). Supervisa subsecretaría de educación zona norte aplicación de filtros sanitarios en escuelas. http://www.cambio.gob.mx/spip.php? article 14794

Gobierno del Estado de Chihuahua. (2020c). Atiende secretaría de educación medidas preventivas en escuelas para evitar coronavirus. http://www.cambio.gob.mx/spip.php?article 14721

González, I. (7 de Abril de 2020). Más maquilas en paro; ya suman 100. El Diario. https://diario.mx/economia/mas-maquilas-en-paro-ya-suman-100-202004071649208.html.

Gudi, S. K. y Tiwari, K. K. (2020). Preparedness and lessons learned from the novel coronavirus disease. International Journal of Occupational and Environmental Medicine, 11(2), 108-112. https://doi.org/10.34172/ijoem.2020.1977

Guerra, A. (21 de febrero de 2020). Logra estado entrega de 80 millones de desayunos escolares. El Heraldo de Juárez. https://www.elheraldodejuarez.com.mx/local/logra-estado-entregade-80-millones-de-desayunos-escolares-4870381.html

Gutiérrez, A. (28 de agosto de 1999). La generación de la maquila abandonó a sus hijos Ciudad Juárez: Las mujeres, del hogar a la línea de ensamblaje. Proceso.

https://www.proceso.com.mx/181324/la-generacion-de-la-maquila-abandono-a-sushijos-ciudad-juarez.

IMIP. (2019). Radiografía socioeconómica del municipio de Juárez 2018, así comenzó 2019. https://www.imip.org.mx/descargas/Radiografia2019.pdf.

INEE. (2015). Los docentes en México. Informe 2015. INEE.

INEE. (2016). Infraestructura, mobiliario y materiales de apoyo educativo en las escuelas primarias. INEE.

INEE. (2019a). Panorama educativo de México. Educación básica y media superior. INEE. 
INEE. (2019b). Personal y organización escolar de la escuela primaria mexicana. INEE.

Jarquín, M. (29 de marzo de 2020). La nueva escuela mexicana en tiempos de pandemia. La Jornada. https://www.jornada.com.mx/2020/03/29/opinion/015a1pol

Lara, E. (09 de abril de 2020). Pronostican desbandada hacia la informalidad. El Diario. https://diario.mx/economia/pronostican-desbandada--hacia-la-informalidad-202004081649860.html.

López, M. A. (2019). Menores del poniente viven en pobreza, abandono y con miedo a la violencia. https://yociudadano.com.mx/noticias/menores-del-poniente-viven-en-pobrezaabandono-y-con-miedo-a-la-violencia/

Martínez, H. (26 de noviembre de 2019). Encabeza Juárez en violencia sexual infantil. El Diario. https://diario.mx/juarez/encabeza-juarez-en-violencia-sexual-infantil-201911251592002.html.

Mbembe, J. A. (2011). Necropolítica. Editorial Melusina.

Medina, P. C., Bass, S. y Fuentes, C. M. (2019). La vulnerabilidad social en Ciudad Juárez, Chihuahua, México. Herramientas para el diseño de una política social. Revista INVI, 34(95), 197-223. https://doi.org/10.4067/S0718-83582019000100197

Navarro, C. (2008). El estudio de las políticas públicas. Revista Jurídica de la Universidad Autónoma de Madrid, 17, 231-255.

OMS. (2020a). Declaración sobre la segunda reunión del comité de emergencias del reglamento sanitario internacional acerca del brote del nuevo coronavirus (2019-nCoV).

https://www.who.int/es/news-room/detail/30-01-2020-statement-on-the-secondmeeting-of-the-international-health-regulations-(2005)-emergency-committee-regardingthe-outbreak-of-novel-coronavirus-(2019-ncov)

OMS. (2020b). Preguntas y respuestas sobre la enfermedad por coronavirus (Covid-19).

https://www.who.int/es/emergencies/diseases/novel-coronavirus-2019/advice-forpublic/q-a-coronaviruses

OMS. (2020c). Alocución de apertura del director general de la OMS en la rueda de prensa sobre la Covid19. https://www.who.int/es/dg/speeches/detail/who-director-general-s-openingremarks-at-the-media-briefing-on-Covid-19---11-march-2020

Ornell, F., Schuch, J. B., Sordi, A. O. y Kessler, F. H. (2020). Pandemic fear and Covid-19: Mental health burden and strategies. Brazilian Journal of Psychiatry, 8.

https://doi.org/10.1590/1516-4446-2020-0008

Plan Estratégico de Juárez. (2020). Informe. Pobreza en Juárez 2020.

https://planjuarez.org/documentos/informe-pobreza-en-juarez-2020/

Rodríguez, J. A., Guevara, A. y Viramontes, E. (2017). Síndrome de burnout en docente. Revista de Investigación Educativa de la REDIECH, 14, 45-68.

Rodríguez-Morales, A. J., Sánchez-Duque, J. A., Hernández, S., Pérez-Díaz, C. E., Villamil-Gómez, W. E., Méndez, C. A., . . Escalera-Antezana, J. P. (2020). Preparación y control de la enfermedad por coronavirus 2019 (Covid-19) en América Latina. Acta Médica Peruana, 37(1), 3-7. https://doi.org/10.35663/amp.2020.371.909

Ruiz, M. y Aguirre, G. (2015). Etnografía virtual, un acercamiento al método y a sus aplicaciones. Estudios sobre las Culturas Contemporáneas, 21(41), 67-69.

Sandoval, C. A. (1996). Investigación cualitativa. Instituto Colombiano para el Fomento de la Educación Superior. 
Schmelkes, S. (31 de Marzo de 2020). Clases digitales marcarán una brecha de aprendizaje. La Jornada. https://www.jornada.com.mx/ultimas/sociedad/2020/03/31/clases-digitalesmarcaran-una-brecha-de-aprendizaje-schmelkes-5346.html

SEP. (2019a). Calendario escolar 2019-2020.

https://www.gob.mx/sep?tab=Calendario\%20escolar\%202019-2020

SEP. (2019b). Principales cifras del sistema educativo nacional 2018-2019. https://www.planeacion.sep.gob.mx/

SEP. (2020a). Lineamientos para prevenir enfermedades respiratorias (Covid-19) en el entorno escolar. https://drive.google.com/file/d/1VkF4Zvgf1UYAfN6xW-GgsE2mgncFswD1/view

SEP. (2020b). Comunicado conjunto No. 3 Presentan salud y SEP medidas de prevención para el sector educativo nacional por Covid-19. https://www.gob.mx/sep/articulos/comunicado-conjuntono-3-presentan-salud-y-sep-medidas-de-prevencion-para-el-sector-educativo-nacionalpor-Covid-19?idiom=es

SEP. (2020c). Aprende en casa por TV y en línea. Capacitación para maestras y maestros del Sistema educativo nacional en competencias digitales.

http:/ / formacionycapacitaciondigitales.televisioneducativa.gob.mx/

SEP. (2020d). Boletín No. 72 de acuerdo con la secretaría de salud, la SEP instrumenta las medidas preventivas por Covid-19. https://www.gob.mx/sep/articulos/boletin-no-72-de-acuerdocon-la-secretaria-de-salud-la-sep-instrumenta-las-medidas-preventivas-por-Covid-19

SEP. (20 de marzo de 2020e). Boletín No. 75 transmitirán sistemas públicos de comunicación contenidos educativos durante el receso escolar preventivo por Covid-19.

https://www.gob.mx/sep/es/articulos/boletin-no-75-transmitiran-sistemas-publicos-decomunicacion-contenidos-educativos-durante-el-receso-escolar-preventivo-por-Covid19? idiom $=\mathrm{es}$

SEP. (23 de marzo de 2020f). Boletín No. 76 convoca SEP a participar en educación a distancia durante receso escolar. https://www.gob.mx/sep/es/articulos/boletin-no-76-convoca-sep-aparticipar-en-educacion-a-distancia-durante-receso-escolar?idiom=es

SEP. (28 de marzo de 2020g). Boletín No. 82 Lanza SEP programa de capacitación en competencias digitales para docentes del sistema educativo nacional.

https://www.gob.mx/sep/es/articulos/boletin-no-82-lanza-sep-programa-decapacitacion-en-competencias-digitales-para-docentes-del-sistema-educativonacional? idiom $=\mathrm{es}$

SEP. (2020h). Guía de trabajo consejo técnico escolar. sesión extraordinaria. preescolar, primaria y secundaria.

http://educacionbasica.sep.gob.mx/consejos_tecnicos_escolares/default/pub?id=1047\&n omactividad $=$ Sesi\%C3\%B3n+Extraordinaria +

SEP. (2020i). Propuestas de actividades para reforzar los aprendizajes esperados durante el aislamiento preventivo (preescolar, primaria y secundaria). Acompañamiento de las familias a los estudiantes. SEP.

Secretaría de Salud. (31 de marzo de 2020). Consejo de salubridad general declara emergencia sanitaria nacional a epidemia por coronavirus Covid-19. https://www.gob.mx/salud/prensa/consejode-salubridad-general-declara-emergencia-sanitaria-nacional-a-epidemia-por-coronavirusCovid-19-239301

Universidad Autónoma de Ciudad Juárez. (2020). Crea UACJ el Programa de continuidad académica virtual. https://comunica.uacj.mx/18-03-2020/9719 
Wang, G., Zhang, Y., Zhao, J., Zhang, J. y Jiang, F. (2020). Mitigate the effects of home confinement on children during the Covid-19 outbreak. The Lancet, 395(10228), 945-947. https://doi.org/10.1016/So140-6736(20)30547-X

\section{Breve CV de los autores}

\section{Evangelina Cervantes Holguín}

Profesora del Departamento de Humanidades de la Universidad Autónoma de Ciudad Juárez (UACJ) y Coordinadora del Centro Chihuahuense de Estudios de Posgrado, Unidad Juárez. Doctora en Educación, Maestra en Desarrollo Educativo, Licenciada en Derecho y Licenciada en Educación Preescolar. Su trayectoria en investigación se centra en el trabajo y formación docente, política educativa y didácticas especializadas. Es autora de diversos libros, capítulos y artículos científicos relacionados con el área. Responsable de diferentes proyectos de investigación a nivel local y estatal. Actualmente es miembro del Cuerpo Académico de Estudios de Educación y Ciencias Sociales. Coordinadora del Centro de Investigación Educativa de la UACJ. ORCID ID: https://orcid.org/00ooo001-6980-22 10. Email: evangelina.cervantes@uacj.mx

\section{Pavel Roel Gutiérrez Sandoval}

Profesor-Investigador adscrito al Programa de Licenciatura en Educación de la Universidad Autónoma de Ciudad Juárez (UACJ) en la División Multidisciplinaria de Nuevo Casas Grandes, Chihuahua, México. Doctor en Educación, Maestro en Ciencias Sociales para el Diseño de Políticas Públicas y Licenciado en Economía. Autor de libros, capítulos y artículos científicos acerca de la política educativa, el género y las artes. Investigador en diferentes proyectos a nivel local y estatal. Actualmente es miembro del Cuerpo Académico de Estudios de Educación y Ciencias Sociales. Responsable de la Unidad Técnico-Experimental en Fonoaudiología, Semántica-Léxica y Didáctica Musical. Coordinador de Diplomado de Especialización en Educación Musical Aplicada de la UACJ. ORCID ID: https://orcid.org/0000-0003-0437-1549. Email: pavel.gutierrez@uacj.mx 